\section{Commentary: Multiple hit model: Treating multivessel coronary disease and ischemic mitral regurgitation}

\author{
Carlos E. Diaz-Castrillon, MD, ${ }^{\mathrm{a}}$ and \\ Ibrahim Sultan, MD ${ }^{\mathrm{a}, \mathrm{b}}$
}

According to the Society of Thoracic Surgeons adult database, there were 165,405 mitral valve (MV) procedures performed in 1082 centers during the 2014-2018 period, of which $52.3 \%$ were MV repairs. ${ }^{1}$ This group of course is rather heterogenous and includes patients with both degenerative and functional MV disease. Functional MV regurgitation, commonly represented by ischemic mitral valve regurgitation (IMR), may present with a dilated annulus with or without a restricted posterior leaflet. Although some observational studies have shown that secondary MV regurgitation confers a relatively poor prognosis to patients with left ventricular (LV) dysfunction and that MV repair is preferable than MV replacement in the short term, this has been debunked by randomized controlled trials that have demonstrated superior durability of MV replacement for IMR. ${ }^{2}$

In this issue of the Journal, Kainuma and colleagues ${ }^{3}$ addressed a persistent question by describing the relationship between performing a restrictive mitral annuloplasty for IMR. Specifically, the study's main objective was to determine the effect of having multiple percutaneous

From the a'Division of Cardiac Surgery, Department of Cardiothoracic Surgery, University of Pittsburgh; and ${ }^{\mathrm{b}} \mathrm{Heart}$ and Vascular Institute, University of Pittsburgh Medical Center, Pittsburgh, Pa.

Disclosures: I.S. receives institutional research support from Medtronic and AtriCure. These conflicts are unrelated to this article. C.E.D.-C. reported no conflicts of interest.

The Journal policy requires editors and reviewers to disclose conflicts of interest and to decline handling or reviewing manuscripts for which they may have a conflict of interest. The editors and reviewers of this article have no conflicts of interest.

Received for publication July 24, 2021; revisions received July 24, 2021; accepted for publication July 26, 2021; available ahead of print Aug 13, 2021.

Address for reprints: Ibrahim Sultan, MD, Division of Cardiac Surgery, Department of Cardiothoracic Surgery, University of Pittsburgh, Center for Thoracic Aortic Disease, Heart and Vascular Institute, University of Pittsburgh Medical Center, 5200 Centre Ave, Suite 715, Pittsburgh, PA 15232 (E-mail: sultani@upmc.edu). JTCVS Open 2021;7:207-8

2666-2736

Copyright (C) 2021 The Author(s). Published by Elsevier Inc. on behalf of The American Association for Thoracic Surgery. This is an open access article under the CC BY-NC-ND license (http://creativecommons.org/licenses/by-nc-nd/4.0/).

https://doi.org/10.1016/j.xjon.2021.07.028

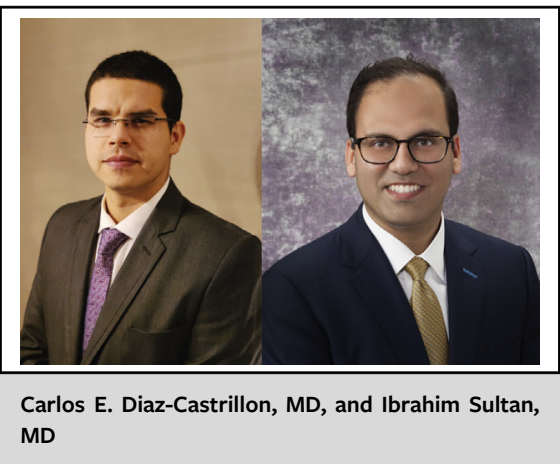

\section{CENTRAL MESSAGE \\ Real-world data highlight the relevance of choosing the best initial revascularization strategy possible in patients with CAD and concomitant ischemic MR.}

coronary intervention (PCI) before MV repair on allcause mortality and heart failure readmission rates among patients with ischemic cardiomyopathy. To meet that end, they analyzed 309 patients with chronic MR over a period of 16 years, comparatively assessing patients from a nonmultiple PCI group (ie, 0 to 1 previous PCI; $\mathrm{n}=211$ ) versus a multiple-PCI group (ie, 2 or more previous PCIs; $n=98)$. It is important to note that approximately two thirds of patients within the nonmultiple PCI group did not receive any previous PCI, with a mean number of $0.3 \pm 0.5$ interventions versus $3.2 \pm 1.5$ in the multiple-PCI group.

The authors should be congratulated for undertaking the challenges in analyzing these data, as it involves the complex relationship between a surgical procedure and the nuances associated with PCI practice variability over a 16 -year period in Japan. The greatest virtue of this study is the appropriateness of the statistical analysis used. First, by using a mixed-effect regression model, the authors were able to demonstrate less of an improvement in LV function parameters over the follow-up period in patients from the multiple-PCI group accounting for the repeated measurement structure of the dataset. In addition, the authors tried to obtain unbiased estimates of the average effects of multiple PCIs on the primary end points by using inverse probability of treatment weighting for propensity score matching, showing a greater risk of all-cause mortality and composite adverse events for patients with multiple PCIs. 
Nevertheless, care should be taken when analyzing these results, given the risk of having overlooked the assumption of Exchangeability or Ignorable treatment assignment, which states that one should have access (measured) to most of the variables that affect treatment selection and outcomes. Although the authors included variables that are highly associated with the primary end points, such as European System for Cardiac Operative Risk Evaluation II, nature of the procedure (emergency indication), preoperative intra-aortic balloon pump, redo operation, diabetes status, renal dysfunction, and LV ejection fraction, there is considerable risk of an unbalanced distribution of important unmeasured confounders. Factors such as the date of the PCI, interventional cardiology expertise, and type of PCI all have important implications on the clinical practice variability of the treatment (exposure) being evaluated.

Additionally, the severity of the ischemic cardiomyopathy remains to be the main source of uncertainty. Although the authors made an insightful comment about it in the limitations, there are some important aspects that deserve further comment. Intuitively, it can be argued that having had multiple PCIs can be translated into having a more complex coronary artery disease (CAD); this is especially true, given the high proportion of patients without PCI in the reference group. Additional information, such as describing the temporal relationship of the CAD diagnosis and MV repair, the type of CAD, differentiating single-stage multivessel PCI versus staged multivessel PCI or the proportion of complete of revascularization achieved in the multivessel PCI group, would have all been important in delineating the impact of the MV repair. For example, even though both groups had the same baseline distribution in terms of moderate/severe MV regurgitation and LV ejection fraction, the fact that $85 \%$ of nonmultiple PCI group patients had a concomitant coronary artery bypass grafting $(\mathrm{CABG})$ procedure should make the reader question how much of the observed outcome is the result of a better revascularization strategy. The fact that $\mathrm{CABG}$ is associated with a greater proportion of complete revascularization than with PCI may have confounded some of these results. ${ }^{4-7}$ Furthermore, patients with incomplete revascularization have a greater risk for poor outcomes regardless of revascularization strategy, ${ }^{8,9}$ which may explain why optimal revascularization may suffice in some patients with IMR. Finally, randomized controlled data comparing CABG plus MV repair versus $C A B G$ alone among patients with moderate IMR had not demonstrated significant differences in the LV reverse remodeling between the groups at 2 years. ${ }^{10}$

Finally, the readers should be aware of the external validity of this results, since there are significant differences in the PCI use patterns between Japan and the United States. Recent reports have shown that while PCI volume has increased in both countries, Japanese physicians perform more elective PCIs with lower use of pre-PCI stress testing in contrast to the United States. ${ }^{11}$ As the authors stated, the overuse of PCI can affect the outcomes for subsequent MV surgery not only by delaying referral but perhaps also by overtreating patients. A recent meta-analysis including recent large contemporary randomized controlled trials examining the role of PCI in different scenarios of CAD (COMPLETE [Culprit-Only Revascularization Strategies to Treat Multivessel Disease after Early PCI for STEMI] and ISCHEMIA [International Study of Comparative Health Effectiveness with Medical and Invasive Approaches] trials) showed a differential effect of PCI effectiveness in relation to the CAD type, where PCI reduces all-cause and cardiovascular mortality in patients with unstable CAD only but had no impact on these end points in patients with stable CAD. ${ }^{12}$ However, as the authors state, these real-world data should call heart teams' attention to the importance of comprehensive discussions when deciding the best initial revascularization strategy in patients with ischemic MR with concomitant CAD.

\section{References}

1. Vemulapalli S, Grau-Sepulveda M, Habib R, Thourani V, Bavaria J, Badhwar V. Patient and hospital characteristics of mitral valve surgery in the United States. JAMA Cardiol. 2019;4:1149-55.

2. Acker MA, Parides MK, Perrault LP, Moskowitz AJ, Gelijns AC, Voisine P, et al. Mitral valve repair versus replacement for severe ischemic mitral regurgitation. $N$ Engl J Med. 2014;370:23-32.

3. Kainuma S, Toda K, Miyagawa S, Yoshioka D, Kawamura T, Kawamura A, et al. Multiple percutaneous coronary interventions worsen outcomes for subsequent surgical correction of chronic ischemic mitral regurgitation. J Thorac Cardiovasc Surg Open. 2021;7:195-206.

4. Head SJ, Mack MJ, Holmes DR, Mohr FW, Morice M-C, Serruys PW, et al. Incidence, predictors and outcomes of incomplete revascularization after percutaneous coronary intervention and coronary artery bypass grafting: a subgroup analysis of 3-year SYNTAX data. Eur J Cardiothorac Surg. 2012;41:535-41.

5. Bangalore S, Guo Y, Samadashvili Z, Blecker S, Xu J, Hannan EL. Everolimuseluting stents or bypass surgery for multivessel coronary disease. $N$ Engl J Med. 2015;372:1213-22.

6. Bianco V, Kilic A, Mulukutla S, Gleason TG, Kliner D, Allen CC, et al. Percutaneous coronary intervention versus coronary artery bypass grafting in patients with reduced ejection fraction. J Thorac Cardiovasc Surg. 2021;161:1022-31.e5.

7. Mulukutla SR, Gleason TG, Sharbaugh M, Sultan I, Marroquin OC, Thoma F, et al. Coronary bypass versus percutaneous revascularization in multivessel coronary artery disease. Ann Thorac Surg. 2019;108:474-80.

8. Ahn J-M, Park D-W, Lee CW, Chang M, Cavalcante R, Sotomi Y, et al. Comparison of stenting versus bypass surgery according to the completeness of revascularization in severe coronary artery disease. JACC Cardiovasv Interv. 2017;10: 1415-24.

9. Bianco V, Kilic A, Aranda-Michel E, Serna-Gallegos D, Ferdinand F, DunnLewis $\mathrm{C}$, et al. Complete revascularization during coronary artery bypass grafting is associated with reduced major adverse events. J Thorac Cardiovasc Surg. June 9, 2021 [Epub ahead of print].

10. Michler RE, Smith PK, Parides MK, Ailawadi G, Thourani V, Moskowitz AJ, et al. Two-year outcomes of surgical treatment of moderate ischemic mitral regurgitation. N Engl J Med. 2016;374:1932-41.

11. Inohara T, Kohsaka S, Spertus JA, Masoudi FA, Rumsfeld JS, Kennedy KF, et al. Comparative trends in percutaneous coronary intervention in Japan and the United States, 2013 to 2017. J Am Coll Cardiol. 2020;76:1328-40.

12. Chacko L, Howard JP, Rajkumar C, Nowbar AN, Kane C, Mahdi D, et al. Effects of percutaneous coronary intervention on death and myocardial infarction stratified by stable and unstable coronary artery disease: a meta-analysis of randomized controlled trials. Circ Cardiovasc Qual Outcomes. 2020;13:e066363. 